\title{
Assessment and Development of the Antifungal Agent Caspofungin for Aerosolized Pulmonary Delivery
}

\author{
Iching G. Yu and David M. Ryckman * \\ Trilogy Therapeutics, Inc., San Diego, CA 92130, USA; gyu@trilogytherapeutics.com \\ * Correspondence: dryckman@trilogytherapeutics.com
}

Citation: Yu, I.G.; Ryckman, D.M. Assessment and Development of the Antifungal Agent Caspofungin for Aerosolized Pulmonary Delivery. Pharmaceutics 2021, 13, 504. https:// doi.org/10.3390/pharmaceutics13040504

Academic Editor: Stefano Giovagnoli

Received: 16 March 2021

Accepted: 2 April 2021

Published: 7 April 2021

Publisher's Note: MDPI stays neutral with regard to jurisdictional claims in published maps and institutional affiliations.

Copyright: (C) 2021 by the authors. Licensee MDPI, Basel, Switzerland. This article is an open access article distributed under the terms and conditions of the Creative Commons Attribution (CC BY) license (https:/ / creativecommons.org/licenses/by/ $4.0 /)$.

\begin{abstract}
Invasive Pulmonary Aspergillosis (IPA) and Pneumocystis jiroveci Pneumonia (PCP) are serious fungal pulmonary diseases for immunocompromised patients. The brand name drug CANCIDAS $^{\circledR}$ (Caspofungin acetate for injection) is FDA approved to treat IPA, but is only $40 \%$ effective. Efficacious drug levels at the lung infection site are not achieved by systemic administration. Increasing the dose leads to toxicity. The objective, here, is to reformulate caspofungin for aerosolization to high drug concentration by lung targeted delivery and avoid systemic distribution. Described in this paper is a new, room temperature-stable formulation that meets these goals. The in vitro antifungal activity, solid state and reconstituted stability, and aerosol properties of the new formulation are presented. In addition, pharmacokinetic parameters and tissue distribution data are determined from nose-only inhalation studies in rats. Plasma and tissue samples were analyzed by High Performance Liquid Chromatography-tandem Mass Spectrometry (HPLC-MS-MS). Inhaled drug concentrations for caspofungin Active Pharmaceutical Ingredient (API), and the new formulation, were compared at the same dose. In the lungs, the parameters $C_{\max }$ and Area Under Curve (AUC) showed a $70 \%$, and $60 \%$, respective increase in drug deposition for the new formulation without significant systemic distribution. Moreover, the calculated pharmacodynamic indices suggest an improvement in efficacy. These findings warrant further animal toxicology studies and human clinical trials, with inhaled caspofungin, for treating IPA.
\end{abstract}

Keywords: inhalation; pulmonary drug delivery; caspofungin; antifungal; formulation; peptide(s); chemical stability; solid-state stability; pharmacokinetic/pharmacodynamic (PK/PD) correlation

\section{Introduction}

Fungal pulmonary infections, caused by Aspergillus or Pneumocystis jiroveci, are serious diseases that devastate immunocompromised patients who receive chemotherapy or immunosuppressive agents, associated with their illness, as well as HIV patients. Ubiquitous airborne spores are inhaled and become established in the lung [1]. The spores germinate and lead to hyphal growth that produce the conidiophores, which in turn, generate additional spores that continue to exponentially reproduce the cycle. For healthy populations, alveolar macrophages in the lung remove these spores efficiently. Patients with compromised immune systems, due to chemotherapy or immunosuppressive agents, cannot eradicate spores like healthy individuals. Aspergillus propagates very rapidly in these patients' lungs. One multicenter study found that, after an IPA diagnosis, the medium time to death was 16 days [2]. The overall case fatality rate, even with the treatment, can reach $86 \%$ in bone marrow transplant patients [3]. Despite the high mortality of Aspergillus infections, current systemic IPA treatments only provide modest efficacy for all patients averaging between $40-50 \%$.

Morphologically Aspergillus grows and propagates within the lung cavity. Data from the Prospective Antifungal Therapy Alliance (PATH Alliance) registry indicated that 76\% of patients had Aspergillus infection confined exclusively in the lung [4]; another study showed $89 \%$ of patients had exclusive pulmonary infection [2]. In a previous animal 
study with the antifungal agent caspofungin showed that only a small percentage (5\%) of drug delivered intravenously to rats was detected in the lung tissues [5]. This may explain low human efficacy ( $40 \%$ ) of caspofungin in treating IPA. Drug concentration in lung may be more relevant to human efficacy than plasma concentrations. It is likely that an inhaled approach with caspofungin can increase drug concentration in the lung and could make a positive impact on human efficacy. Further advocacy for this approach was published in a recent letter to the International Journal of Infectious Diseases, in order to treat Pneumocystis jiroveci Pneumonia (PCP) with inhaled caspofungin [6]. An inhaled caspofungin formulation could be used to treat fungal pulmonary infections, such as IPA and PCP.

Caspofungin is the first in class echinocandin and shows superior in vitro activity against Aspergillus among the three classes of antifungals namely polyenes, azoles and echinocandins [5]. Caspofungin specifically targets the tips and branch points of the growing hyphae, the site of $\beta-(1,3)$-D-glucan synthase that form the major component of the Aspergillus and Pneumocystis jiroveci cell wall. Here, it disrupts the integrity of the fungal cell wall, which loses its mechanical strength, and becomes destroyed by intracellular osmotic pressure. A topical application of the infection site may provide superior efficacy, as observed in the in vitro studies.

Caspofungin for injection (tradename: CANCIDAS ${ }^{\circledR}$ ) is sold by Merck \& Co., Inc. The approved CANCIDAS ${ }^{\circledR}$ dose is a $70 \mathrm{mg}$ loading dose and then $50 \mathrm{mg} /$ daily. Previous intravenous (IV) studies with caspofungin in animals have shown that IV administered drug only delivers about $5 \%$ of the drug level in blood to the lungs. Moreover, the drug level in the lung did not meet pharmacokinetic (PK) and pharmacodynamic (PD) targets required for clinical efficacy [5]. Most of the IV drugs is distributed to other sensitive target organs, such as the liver and kidneys, which if given in higher doses, can lead to toxicities. The low drug distribution to the infection site (lung) may explain why good in vitro activity is not mirrored in clinical efficacy [7]. In a clinical study treating IPA, patients received a caspofungin dose that was three times higher than the approved IV dose. This high dose group ( $200 \mathrm{mg} /$ day intravenously) showed a $60 \%$ response rate (either complete response or partial response), whereas the standard dose group only showed a $44 \%$ favorable response [8]. The high dose group showed a 36\% improved response rate over the standard dose group, but $65 \%$ of patients in the high dose group presented with liver toxicity, including elevated liver enzymes and liver failure. No liver enzyme abnormalities were observed for patients in the standard dose group. It is reasonable to conclude that patients in the high dose group had more drug delivered to the lungs, resulting in more favorable responses, but at the cost of liver toxicity. An ideal approach would be to increase the drug concentration in the lungs without increasing systemic distribution. An inhaled formulation for caspofungin may accomplish this goal.

The CANCIDAS ${ }^{\circledR}$ lyophilized formulation is unstable at room temperature and must be stored at $2-8{ }^{\circ} \mathrm{C}$. It is reconstituted for daily IV use only, to give a $10 \mathrm{mg} / \mathrm{mL}$ caspofungin solution. Moreover, this reconstituted solution is only stable for $1 \mathrm{~h}$ at $\leq 25^{\circ} \mathrm{C}$. The lack of room temperature stability of CANCIDAS ${ }^{\circledR}$ makes it unlikely to be used for inhalation and a room temperature stable formulation is critical for delivering a high dose of caspofungin directly to the lung to achieve better efficacy. Caspofungin stability studies show that the primary degradation route is hydrolysis and subsequent dimerization of the hydrolyzed product, leading to the product failing specification [9]. Protection from water is a concern [9]. Therefore, we have chosen to examine polyvinylpyrrolidone (PVP) as an alternate excipient to the commercial formulation. Povidone or PVP is widely used in the food and cosmetic industries. In addition, PVP is an excipient in many oral and IV drugs and approved for nasal inhalants such as $P V P-I_{2}[10]$. Active research and development are underway for the use of PVP in metered dose inhalers and spray dried formulation for analgesics and antipyretics [11]. For an inhaled formulation, PVP has several desirable properties, including taste masking for an inhaled formulation. Furthermore, PVP is highly water soluble and can bind to at least $40 \%$ of its weight in water while in solid state [12]. 
Hydrolytic degradation of caspofungin may be inhibited by PVP when it favorably sequestering residual water in the lyophile cake, and protects caspofungin from exposure to water and degradation.

In addition to drug efficacy and mechanism of action, there are several factors to consider when developing an inhaled drug, which include the chemical properties of the drug, stability of the formulation, drug retention time in lung, oral bioavailability and aerosol particle size. Here, we present a new formulation and route of delivery for caspofungin that satisfy these criteria. We also show data that demonstrate the ability to deliver a high dose of drug topically to the lung without widespread systemic distribution.

\section{Materials and Methods}

\subsection{In Vitro Antifungal Activity with TTI-016, TTI-017 Compared to CANCIDAS ${ }^{\circledR}$ and API}

Antifungal potency of the test article(s) was measured using the in vitro broth microdilution assay under test conditions described by the Clinical and Laboratory Standards Institute. Minimum Inhibitory Concentration (MIC) is defined as the lowest concentration of an agent that causes a specified reduction in visible growth of the microorganism. Minimum Effective Concentration (MEC) is defined as the lowest concentration of an agent that leads to the growth of small, rounded, compact hyphal forms, as compared to the hyphal growth typically seen in the growth control well. MIC values were determined for 9 Candida spp., and MEC values were determined for filamentous fungus species (Aspergillus fumigatus and Trichophyton rubrum). Details of the test article preparations and methodologies are described in Supplementary Material S1. CANCIDAS ${ }^{\circledR}$ and caspofungin API were used to compare antifungal potency of laboratory formulation code designations TTI-016 and TTI-017, and Amphotericin B was used as an experimental positive control.

\subsection{Caspofungin Stability Studies}

For stability studies, caspofungin was purchased from BrightGene Bio-Medical Technology Co. Ltd. (Jiangsu, China) and Chunghwa Chemical Synthesis and Biotech Co. Ltd. (New Taipei City, Taiwan). Polyvinylpyrrolidone K30 was purchased from Spectrum Chemicals (Gardena, CA, USA). Lyophilization was accomplished using a VirTis benchtop manifold lyophilizer (SP Scientific, Stone Ridge, NY, USA) under vacuum of $<50$ mTorr. Details for the lyophilization process and formulation preparations are presented in Supplementary Material S2. High-performance liquid chromatography (HPLC) analysis was carried out on a Waters 2695 separations module (Waters Corporation, Milford, MA, USA) equipped with an autosampler and a Waters 996 photodiode array detector. For impurity determinations a Waters Symmetry (Waters Corporation, Milford, MA, USA) C18 $3.5 \mu \mathrm{m}$, $4.6 \times 75 \mathrm{~mm}$ column was used. For weight-weight assay a Waters Symmetry C18 Column (Waters Corporation, Milford, MA, USA), $3.5 \mu \mathrm{m}, 4.6 \mathrm{~mm} \times 100 \mathrm{~mm}$ column was employed. Sample preparation, the HPLC conditions, mobile phase and gradients are described in Supplementary Material S2. Reconstituted stability analyses were analyzed using the above HPLC methods. Details of the procedures are described in Supplementary Material S2.

\subsection{Aerosol Characterization}

Aerosol particle size distribution was determined once with a quartz crystal microbalance (QCM) cascade impactor (California Measurements Inc., Sierra Madre, CA, USA) equipped with 10 stages to collect size-segregated samples. The mass median aerodynamic diameter (MMAD) and geometric standard deviation (GSD) were calculated from the mass accumulated on each collection stage of the QCM. Each formulation was tested by aerosolizing it with a PARI LC Star nebulizer (PARI Respiratory Equipment, Inc., Midlothian, VA, USA) connected to compressed air at 28 psi. The air flow to the nebulizer was about $6.2 \mathrm{~L} / \mathrm{min}$. Approximately $7 \mathrm{~mL}$ of the test formulation solution was placed in the nebulizer, weighed and connected to the air supply for aerosolization. The nebulizer was operated for $12 \mathrm{~min}$, and post weighed. The generated aerosol was delivered into a plenum with a narrow opening. A stream of test aerosol was sampled from the plenum for 
particle size determination. A Quartz Crystal Microbalance based cascade impactor (TSI Inc., Shoreview, MN, USA) was used for these determinations. Details of the formulation preparations are described in Supplementary Material S3.

\subsection{Inhalation Pharmacokinetic Studies with Caspofungin Formulation}

The study protocols (No. 2635, approval date: 10 May 2016) were approved by the institutional review board at Illinois Institute of Technology Research Institute (IITRI). The study also complied with all applicable sections of the Animal Welfare Act (AWA; Title 9, Code of Federal Regulations), the Public Health Service Policy on Humane Care and Use of Laboratory Animals (National Institutes of Health's Office of Laboratory Animal Welfare, 2002), and the Guide for the Care and Use of Laboratory Animals (National Research Council, 2011).

Sprague-Dawley derived male rats $\left[\mathrm{Crl}: \mathrm{CD}^{\circledR}(\mathrm{CD}) \mathrm{Br}\right]$ were obtained from Charles River Laboratories, Inc., Wilmington, MA, USA, for use in this study. The animals were approximately 8.5 weeks old at the start of the first exposure to the test article. The animals were randomized into 15 animals per group based on the body weight. Each group was given a single dose of test article. Caspofungin was administered to rats at a target dose of $2 \mathrm{mg} / \mathrm{kg}$ by nose only inhalation (by deposition) or intravenously to determine the plasma and tissue concentrations and pharmacokinetics.

The dose targeted for deposition via inhalation was $2 \mathrm{mg} / \mathrm{kg}$ and was calculated based on this equation,

$$
\text { Deposited dose }=(\mathrm{C} \times \mathrm{RMV} \times \mathrm{T} \times \mathrm{DF}) / \mathrm{BW}
$$

where $\mathrm{C}$ is the average caspofungin concentration in the exposure atmosphere during the exposure period, RMV is the respiratory minute volume, $\mathrm{T}$ is the exposure time, $\mathrm{DF}$ is the deposition fraction (assumed to be $10 \%$ per FDA guidelines) and BW is the average animal body weight on exposure day.

The dose for IV administration was calculated based on the body weight of each animal:

$$
\text { Delivered dose }=\mathrm{W} \times 2 \mathrm{mg} / \mathrm{kg}
$$

where $\mathrm{W}$ is animal weight $(\mathrm{kg})$.

Whole blood samples were collected from three animals per time-point at approximately $0.5,1,2,4,8,12,24$ and $48 \mathrm{~h}$ and 7 days after dose administration for plasma drug level determination. Rats were anesthetized with $70 \% \mathrm{CO} 2 / 30 \%$ air and blood was collected from the retro-orbital plexus and placed into tubes containing anticoagulant (EDTA). Blood samples were placed on ice immediately following collection and processed (i.e., centrifuged) to plasma. The samples were then stored frozen (at approximately $-70{ }^{\circ} \mathrm{C}$ ) until analyzed. Tissue specimens (lung, liver and kidney) were collected from three animals per time point at $0.5,2,24$ and $48 \mathrm{~h}$ and 7 days after dose administration. All tissue specimens were stored frozen at approximately $-70{ }^{\circ} \mathrm{C}$ until analyzed.

Test atmosphere generation, test atmosphere monitoring, aerosol particle distribution, test article administration, toxicology methods, and the bioanalytical method and analysis are described in the prior study and Supplementary Material S4 [5].

\subsection{Statistical Analysis}

$t$-test was used to analyze the statistical significance of the difference between groups. A difference of $p<0.05$ was considered significance.

\section{Results}

Lyophilized formulations of PVP and caspofungin were prepared in order to examine the in vitro activity, stability, aerosol properties, as well as the inhaled pharmacokinetics and distribution in targeted organs. We formulated compositions with 1:1, 2:1 and 4:1 ratios of PVP:caspofungin, using water as the lyophile diluent, but we selected the high 
4:1 ratio of PVP:caspofungin for in vitro testing to investigate any abnormalities caused by the PVP. Normal saline and phosphate buffered (PBS) saline were used as the lyophile diluent for TTI-016 and TTI-017. Reconstitution of the lyophilized cakes with normal saline was prepared in both TTI-016 and TTI-017. CANCIDAS ${ }^{\circledR}$ was reconstituted per label instructions and caspofungin API was dissolved in normal saline.

\subsection{In Vitro Antifungal Activity}

Following incubation, the test plates were visually examined and wells were scored for growth or complete growth inhibition to define the MIC values. Microscopy examination was used to determine the MEC values. Each test substance was evaluated in duplicate and the results are the duplicate test values. Vehicle-control and an active reference agent were used as blank and positive controls, respectively. The formulations TTI-016 and TTI-017 retained anti-fungal activity against the tested Candida, Cryptococcus, Aspergillus and Trichophyton strain as shown in Table 1.

Table 1. MIC or MEC of various formulations against selected fungal species.

\begin{tabular}{|c|c|c|c|c|c|c|c|}
\hline \multirow[b]{2}{*}{ No. } & \multirow[b]{2}{*}{ Species } & \multirow[b]{2}{*}{ Strain ID } & \multicolumn{5}{|c|}{ MIC or $\mathrm{MEC}, \mu \mathrm{g} / \mathrm{mL}$} \\
\hline & & & CANCIDAS $^{\circledR}$ & TTI-016 & TTI-017 & $\begin{array}{l}\text { Caspofungin } \\
\text { Diacetate }\end{array}$ & Amphotericin B \\
\hline 1 & Candida albicans & ATCC44858 & 0.5 & 0.25 & 0.25 & 0.25 & 0.125 \\
\hline 2 & Candida albicans & $\begin{array}{l}\text { ATCC90028 } \\
\text { ATCC90028 }\end{array}$ & 0.25 & 0.25 & 0.25 & 0.25 & 0.125 \\
\hline 3 & Candida albicans & $\begin{array}{c}+50 \% \text { human } \\
\text { serum }\end{array}$ & 0.125 & 0.25 & 0.25 & 0.125 & 0.25 \\
\hline 4 & Candida albicans & $\begin{array}{c}\text { Azole-R } \\
(20183.073)\end{array}$ & 0.25 & 0.25 & 0.25 & 0.25 & 0.125 \\
\hline 5 & Candida albicans & $\begin{array}{c}\text { Azole-R } \\
(20186.025)\end{array}$ & 0.5 & 0.5 & 0.25 & 0.25 & 0.25 \\
\hline 6 & Candida glabrata & ATCC 36583 & 0.25 & 0.5 & 0.25 & 0.25 & 0.125 \\
\hline 7 & Candida krusei & ATCC 6258 & 1 & 1 & 1 & 1 & 0.25 \\
\hline 8 & Candida parapsilosis & ATCC 22019 & 1 & 2 & 1 & 1 & 0.25 \\
\hline 9 & Candida tropicalis & ATCC 200956 & 0.5 & 0.5 & 0.25 & 0.25 & 1 \\
\hline 10 & Aspergillus fumigatus & ATCC 13073 & 0.125 & 0.125 & 0.125 & 0.0625 & 0.25 \\
\hline 11 & Aspergillus fumigatus & ATCC204305 & 0.125 & 0.25 & 0.125 & 0.125 & 0.5 \\
\hline 12 & Trichophyton rubrum & ATCC 10218 & 0.25 & 0.25 & 0.25 & 0.125 & 0.125 \\
\hline
\end{tabular}

MIC minimum inhibitory concentration; MEC minimum effective concentration.

TTI-016 and TTI-017 have similar antifungal activity ( $p=0.56$ and $p=0.34$, respectively) compared to CANCIDAS ${ }^{\circledR}$ against Candida, Aspergillus and Trichophyton as shown in Table 1.

\subsection{Formulation Stability}

The stability of the lyophilized formulations was studied under two sets of temperature conditions, $2-5^{\circ} \mathrm{C}$ and $25^{\circ} \mathrm{C}$. The frozen solutions were lyophilized for $90 \mathrm{~h}$ to reduce the water content of the cake to less than $1.0 \%$ (specifically, TTI-016: $0.87 \%$ and TTI-017: $0.79 \%$ water content). At the specified time points the test articles were reconstituted with normal saline to yield a $10 \mathrm{mg} / \mathrm{mL}$ solution for HPLC assay. For comparison, we also lyophilized caspofungin API alone. The results of these stability tests are shown in Table 2. 
Table 2. Caspofungin formulation stability at storage at $5{ }^{\circ} \mathrm{C}$ and $25^{\circ} \mathrm{C}$.

\begin{tabular}{|c|c|c|c|c|c|c|c|c|c|}
\hline \multirow{4}{*}{$\begin{array}{c}\text { PVP:Caspofungin } \\
\text { Diluent } \\
\text { Time (Months) }\end{array}$} & \multirow[b]{2}{*}{$\begin{array}{l}\text { API (Lyo } \\
\text { Process) }\end{array}$} & \multicolumn{4}{|c|}{$5{ }^{\circ} \mathrm{C}$} & \multicolumn{4}{|c|}{$25^{\circ} \mathrm{C}$} \\
\hline & & TTI-013 & TTI-014 & TTI-016 & TTI-017 & TTI-013 & TTI-014 & TTI-016 & TTI-017 \\
\hline & $\begin{array}{c}0: 1 \\
\text { Water }\end{array}$ & $\begin{array}{c}2: 1 \\
\text { Water }\end{array}$ & $\begin{array}{c}4: 1 \\
\text { Water }\end{array}$ & $\begin{array}{c}4: 1 \\
\text { N-Saline }\end{array}$ & $\begin{array}{c}\text { 4:1 } \\
\text { PBS }\end{array}$ & $\begin{array}{c}2: 1 \\
\text { Water }\end{array}$ & $\begin{array}{c}4: 1 \\
\text { Water }\end{array}$ & $\begin{array}{c}4: 1 \\
\text { N-Saline }\end{array}$ & $\begin{array}{c}4: 1 \\
\text { PBS }\end{array}$ \\
\hline & \multicolumn{9}{|c|}{ HPLC Purity \% } \\
\hline 0 & 95.42 & 98.97 & 99.14 & 99.73 & 99.72 & 98.97 & 99.14 & 99.73 & 99.72 \\
\hline 0.5 & - & - & - & 99.64 & 99.62 & - & - & 99.40 & 99.48 \\
\hline 1 & - & - & - & 99.55 & 99.61 & - & - & 99.23 & 99.36 \\
\hline 2 & - & 98.46 & 99.03 & 99.59 & 99.58 & 96.63 & 97.73 & 98.88 & 98.94 \\
\hline 3 & - & - & - & 99.50 & 99.63 & - & - & 98.06 & 98.32 \\
\hline 6 & - & - & - & 99.54 & 99.52 & - & - & 97.99 & 98.21 \\
\hline 12 & - & - & - & 99.14 & 99.39 & - & - & 97.14 & 96.45 \\
\hline
\end{tabular}

Caspofungin amount of each formulation was measured by HPLC and presented as purity \%.

For comparison and shown in Table 3, are the total impurities reported for CANCIDAS formulation versus the total impurities measured for TTI-016 and TTI-017 at the same time points when stored at $25^{\circ} \mathrm{C}$ [13]. Both TTI-016 and TTI-017 show significantly less total impurity compared to CANCIDAS formulation $(p<0.01)$. There is not a significant difference in total impurities between TTI-016 and TTI-017 $(p=0.73)$.

Table 3. Comparison of total impurities of CANCIDAS formulation and TTI-016 and TTI-017 at $25^{\circ} \mathrm{C}$.

\begin{tabular}{cccc}
\hline \multirow{2}{*}{ Time (Weeks) } & \multicolumn{2}{c}{ Total Impurities \% } \\
& CANCIDAS Formulation ${ }^{\text {a }}$ & TTI-016 $^{* *}$ & TTI-017 $^{* *}$ \\
\hline 0 & 1.93 & 0.27 & 0.28 \\
2 & 2.06 & 0.60 & 0.52 \\
4 & 2.09 & 0.77 & 0.64 \\
\hline
\end{tabular}

${ }^{a}$ US patent 9636407 B2 [13]. The double asterisk $\left({ }^{* *}\right)$ corresponds to significant difference $(p<0.01)$ compared to CANCIDAS formulation.

As shown in Table 4, and of particular significance, is the reconstituted, room temperature, stability of these lyophilized formulations when compared to reconstituted CANCIDAS ${ }^{\circledR}$. According to the Package Insert, reconstituted $10 \mathrm{mg} / \mathrm{mL}$ CANCIDAS ${ }^{\circledR}$ solution is only stable for up to one hour at $\leq 25^{\circ} \mathrm{C}$. TTI-016 and TTI-017, when reconstituted to the same concentration, remained stable for at least seven hours at room temperature. There is no statistically significant difference in the reconstituted solutions of TTI-016 and TTI-017.

Table 4. HPLC purity of reconstituted solution stability of TTI-016 and TTI-017 at $25^{\circ} \mathrm{C}$.

\begin{tabular}{ccc}
\hline Time (h) & HPLC Purity \% & \\
& TTI-016 & TTI-017 \\
\hline 0 & 99.34 & 99.38 \\
4 & 99.25 & 99.33 \\
7 & 99.00 & 99.04 \\
& 98.93 & 98.73 \\
\hline
\end{tabular}

\subsection{Aerosol Properties}

In addition to room temperature stability, an inhaled product must have an appropriate $\mathrm{pH}$, osmolality and aerosol particle size. All the presented formulations (Table 5) met the first two criteria. However, for optimal lung deposition, the aerosol must have a particle size between 1 and 5 microns. Particles smaller than 1 micron can be exhaled and those larger than 5 microns can be swallowed instead of being inhaled. Particle size outside 
this range results in suboptimal lung deposition [14]. TTI-002 falls just outside of this ideal range with a mass median aerodynamic diameter (MMAD) of 0.89 microns (Table 5). TTI-013 and TTI-016 aerosol particle sizes allow the drug to penetrate deeply into the lung.

Table 5. Aerosol properties of formulations.

\begin{tabular}{|c|c|c|c|c|c|}
\hline \multicolumn{6}{|c|}{ Formulation Compositions } \\
\hline Solution Number & API & TTI-002 & TTI-013 & TTI-016 & N-Saline \\
\hline Caspofungin diacetate final concentration, $\mathrm{mg} / \mathrm{mL}$ & 10 & 10 & 10 & 10 & \\
\hline PVP concentration final concentration, $\mathrm{mg} / \mathrm{mL}$ & 0 & 10 & 20 & 40 & \\
\hline PVP K30 /Caspofungin diacetate ratio $(w / w)$ & $0: 1$ & $1: 1$ & $2: 1$ & $4: 1$ & \\
\hline Caspofungin diacetate Stock $(100 \mathrm{mg} / \mathrm{mL})$ in $\mathrm{mL}$ & & 1 & 1 & 1 & $0.9 \%$ Saline \\
\hline PVP K30 Stock $(100 \mathrm{mg} / \mathrm{mL})$ in $\mathrm{mL}$ & & 1 & 2 & 4 & \\
\hline $0.9 \%$ normal saline (approx. volumes) in $\mathrm{mL}$ & & 8 & 7 & 5 & \\
\hline Total (fill to mark in $10 \mathrm{~mL}$ vol flask w saline) & & $10 \mathrm{~mL}$ & $10 \mathrm{~mL}$ & $10 \mathrm{~mL}$ & \\
\hline \multicolumn{6}{|c|}{ Aerosolization Data } \\
\hline Aerosolization time, $\min (\mathrm{A})$ & 12 & 12 & 12 & 12 & 12 \\
\hline Pre wt, $g$ (nebulizer + formulation), B & & 44.8 & 42.8 & 42.9 & 44.7 \\
\hline Post wt, $\mathrm{g}$ (nebulizer + formulation), $\mathrm{C}$ & & 43.0 & 41.0 & 41.3 & 42.6 \\
\hline Dispersion rate, $\mathrm{mg} / \mathrm{min}=(\mathrm{B}-\mathrm{C}) / \mathrm{A}$ & & & & & \\
\hline $\begin{array}{l}\text { (Calculation carried out with unrounded data for pre- } \\
\text { and post-weights) }\end{array}$ & & 149.6 & 151.2 & 137.8 & 169.4 \\
\hline \multicolumn{6}{|c|}{ Aerosol Particle Size Distribution } \\
\hline MMAD $^{\mathrm{a}}$, microns & 1.15 & 0.89 & 1.09 & 1.10 & 0.52 \\
\hline $\mathrm{GSD}^{\mathrm{b}}$ & 2.67 & $3.4-3.8$ & $3.1-3.7$ & $4.6-5.6$ & $2.2-3.3$ \\
\hline
\end{tabular}

${ }^{\mathrm{a}}$ Mass Median Aerodynamic Diameter, ${ }^{\mathrm{b}}$ Geometric Standard Deviation.

\subsection{Pharmacokinetics}

Based on the in vitro activity, solid state and reconstituted stability, and aerosol properties, TTI-016 was selected for further evaluations in the rat inhalation pharmacokinetic studies. Test formulations were prepared, as described and administered at a deposited dose of $2 \mathrm{mg} / \mathrm{kg}$ by IV or nose only inhalation. This dose is the nominal effective dose in rodents [15]. Exposure of male rats to IV CANCIDAS ${ }^{\circledR}$ or inhaled caspofungin API and TTI-016 resulted in no test-article-related mortality, no clinical signs of toxicity, no effects on body weight, and no gross necropsy findings attributable to exposure to the test article. Drug distribution in plasma and organs (lung, kidney and liver) were analyzed by HPLC-MS-MS to determine drug concentration and pharmacokinetics. Table 6 present caspofungin concentrations in lung, plasma, kidney and liver of three cohorts. The data are present as mean values $(n=3) \pm$ Standard Deviation (SD). The cohort administered TTI-016 showed improved drug deposition in lungs by $70 \%$ measured by $\mathrm{C}_{\max }$ compared to the API cohort without increasing systemic exposure, as shown in Table 7 [5]. AUC was calculated for each animal and presented as mean values $(n=3) \pm$ SD. Statistical difference in AUC of each cohort was analyzed using $t$-test. Caspofungin plasma and lung levels in both inhaled API and TTI-016 showed statistical difference from IV CANCIDAS ${ }^{\circledR}$ $(p<0.01$ and $p<0.05$, respectively). The time-dependent concentration curves in lungs highlight the difference in drug concentrations in the lung between the two inhaled cohorts (Figure 1a). Drug concentrations in plasma, kidney and liver for the inhaled groups are similar (Figure $1 \mathrm{~b}-\mathrm{d}$ ). 
Table 6. Caspofungin concentration in rat tissues following inhaled delivery with TTI-016 and API and intravenous delivery with CANCIDAS ${ }^{\circledR}$.

\begin{tabular}{|c|c|c|c|c|c|c|c|c|c|c|c|c|}
\hline \multirow{2}{*}{$\begin{array}{l}\text { Time } \\
\text { (h) }\end{array}$} & \multicolumn{3}{|c|}{ Lung $(\mu \mathrm{g} / \mathrm{g})$} & \multicolumn{3}{|c|}{ Plasma $(\mu \mathrm{g} / \mathrm{mL})$} & \multicolumn{3}{|c|}{ Kidney $(\mu \mathrm{g} / g)$} & \multicolumn{3}{|c|}{ Liver $(\mu \mathrm{g} / \mathrm{g})$} \\
\hline & TTI-016 & API & CANCIDAS & TTI-016 & API & CANCIDAS & TTI-016 & API & CANCIDAS & TTI-016 & API & CANCIDAS \\
\hline 0.5 & $\begin{array}{c}16.17 \pm \\
4.41\end{array}$ & $\begin{array}{c}10.83 \pm \\
0.81\end{array}$ & $\begin{array}{c}0.58 \pm \\
0.07\end{array}$ & $\begin{array}{c}2.2 \pm \\
0.32\end{array}$ & $\begin{array}{c}2.03 \pm \\
0.35\end{array}$ & $\begin{array}{c}11.03 \pm \\
0.47\end{array}$ & $\begin{array}{c}0.11 \pm \\
0.05\end{array}$ & $\begin{array}{c}0.16 \pm \\
0.02\end{array}$ & $\begin{array}{c}0.50 \pm \\
0.00\end{array}$ & $\begin{array}{c}0.04 \pm \\
0.00\end{array}$ & $\begin{array}{c}0.09 \pm \\
0.01\end{array}$ & $0.25 \pm 0.04$ \\
\hline 2 & $\begin{array}{c}18.43 \pm \\
4.37\end{array}$ & $\begin{array}{c}10.37 \pm \\
2.15\end{array}$ & $\begin{array}{c}0.54 \pm \\
0.04\end{array}$ & $\begin{array}{c}2.25 \pm \\
0.46\end{array}$ & $\begin{array}{c}1.93 \pm \\
0.25\end{array}$ & $\begin{array}{c}7.72 \pm \\
0.51\end{array}$ & $\begin{array}{c}0.16 \pm \\
0.03\end{array}$ & $\begin{array}{c}0.16 \pm \\
0.02\end{array}$ & $\begin{array}{c}0.67 \pm \\
0.13\end{array}$ & $\begin{array}{c}0.09 \pm \\
0.02\end{array}$ & $\begin{array}{c}0.13 \pm \\
0.01\end{array}$ & $0.31 \pm 0.02$ \\
\hline 24 & $\begin{array}{c}8.76 \pm \\
1.54\end{array}$ & $\begin{array}{c}5.31 \pm \\
0.40\end{array}$ & $\begin{array}{c}0.18 \pm \\
0.01\end{array}$ & $\begin{array}{c}0.32 \pm \\
0.16\end{array}$ & $\begin{array}{c}0.23 \pm \\
0.10\end{array}$ & $\begin{array}{c}0.80 \pm \\
0.06\end{array}$ & $\begin{array}{c}0.16 \pm \\
0.07\end{array}$ & $\begin{array}{c}0.16 \pm \\
0.07\end{array}$ & $\begin{array}{c}0.50 \pm \\
0.05\end{array}$ & $\begin{array}{c}0.29 \pm \\
0.15\end{array}$ & $\begin{array}{c}0.3 \pm \\
0.06\end{array}$ & $0.66 \pm 0.02$ \\
\hline 48 & $\begin{array}{c}5.4 \pm \\
1.37\end{array}$ & $\begin{array}{c}3.37 \pm \\
0.95\end{array}$ & $\begin{array}{c}0.09 \pm \\
0.01\end{array}$ & $\begin{array}{c}0.09 \pm \\
0.01\end{array}$ & $\begin{array}{c}0.08 \pm \\
0.01\end{array}$ & $\begin{array}{c}0.19 \pm \\
0.03\end{array}$ & $\begin{array}{c}0.07 \pm \\
0.00\end{array}$ & $\begin{array}{c}0.12 \pm \\
0.01\end{array}$ & $\begin{array}{c}0.33 \pm \\
0.02\end{array}$ & $\begin{array}{c}0.13 \pm \\
0.01\end{array}$ & $\begin{array}{c}0.18 \pm \\
0.04\end{array}$ & $0.45 \pm 0.07$ \\
\hline 168 & $\begin{array}{c}0.36 \pm \\
0.11\end{array}$ & $\begin{array}{c}0.39 \pm \\
0.05\end{array}$ & $\begin{array}{c}0.00 \pm \\
0.00\end{array}$ & $\begin{array}{c}0.01 \pm \\
0.00\end{array}$ & $0 \pm 0.00$ & $\begin{array}{c}0.00 \pm \\
0.00\end{array}$ & $\begin{array}{c}0.01 \pm \\
0.00\end{array}$ & $\begin{array}{c}0.00 \pm \\
0.03\end{array}$ & $\begin{array}{c}0.07 \pm \\
0.01\end{array}$ & $\begin{array}{c}0.03 \pm \\
0.01\end{array}$ & $\begin{array}{c}0.02 \pm \\
0.03\end{array}$ & $0.11 \pm 0.01$ \\
\hline
\end{tabular}

Table 7. Caspofungin pharmacokinetics in IV CANCIDAS ${ }^{\circledR}$, inhaled API and inhaled TTI-016. The data are presented as the mean values $(n=3) \pm \mathrm{SD}$.

\begin{tabular}{|c|c|c|c|c|c|c|}
\hline & \multicolumn{6}{|c|}{ Rat Pharmacokinetic Parameters } \\
\hline & \multicolumn{3}{|c|}{ Plasma } & \multicolumn{3}{|c|}{ Lung } \\
\hline & $\begin{array}{c}\text { IV } \\
\text { CANCIDAS }^{\circledR}\end{array}$ & $\begin{array}{l}\text { Inhaled } \\
\text { API }\end{array}$ & $\begin{array}{l}\text { Inhaled } \\
\text { TTI-016 }\end{array}$ & $\begin{array}{c}\text { IV } \\
\text { CANCIDAS }^{\circledR}\end{array}$ & $\begin{array}{l}\text { Inhaled } \\
\text { API }\end{array}$ & $\begin{array}{l}\text { Inhaled } \\
\text { TTI-016 }\end{array}$ \\
\hline $\begin{array}{l}\mathrm{AUC}(24 \mathrm{~h}) \\
\left(\mu \mathrm{g} \cdot \mathrm{h} \cdot \mathrm{mL}^{-1}\right)\end{array}$ & $85.93 \pm 2.96$ & $21.14 \pm 1.31^{* *}$ & $25.43 \pm 3.60 * *$ & $8.88 \pm 0.72$ & $191.02 \pm 27.97 *$ & $329.07 \pm 68.74$ * \\
\hline $\begin{array}{c}\mathrm{AUC}(48 \mathrm{~h}) \\
\left(\mu \mathrm{g} \cdot \mathrm{h} \cdot \mathrm{mL}^{-1}\right)\end{array}$ & $97.72 \pm 3.32$ & $24.84 \pm 2.54^{* *}$ & $30.44 \pm 5.43^{* *}$ & $12.12 \pm 0.88$ & $295.14 \pm 22.02$ * & $498.97 \pm 93.09$ * \\
\hline $\begin{array}{l}\text { AUC }(168 \mathrm{~h}) \\
\left(\mu \mathrm{g} \cdot \mathrm{h} \cdot \mathrm{mL}^{-1}\right)\end{array}$ & $108.96 \pm 1.60$ & $29.45 \pm 3.17^{* *}$ & $36.84 \pm 5.32 * *$ & $17.54 \pm 1.06$ & $520.98 \pm 43.09^{*}$ & $844.05 \pm 154.79 *$ \\
\hline $\operatorname{Kel}\left(\mathrm{h}^{-1}\right)$ & $0.07 \pm 0.01$ & $0.05 \pm 0.01$ & $0.06 \pm 0.01$ & $0.04 \pm 0.00$ & $0.02 \pm 0.00$ & $0.02 \pm 0.00$ \\
\hline t 1/2 (h) & $10.29 \pm 0.84$ & $13.3 \pm 2.54$ & $11.78 \pm 1.71$ & $18.00 \pm 1.00$ & $38.67 \pm 2.52$ & $31.67 \pm 3.51$ \\
\hline$C_{\max }(\mu \mathrm{g} / \mathrm{mL})$ & $11.03 \pm 0.47$ & $2.04 \pm 0.33$ & $2.26 \pm 0.36$ & $0.58 \pm 0.07$ & $10.83 \pm 0.81$ & $18.43 \pm 4.37$ \\
\hline $\mathrm{T}_{\max }(\mathrm{h})$ & 0.5 & 1 & 1 & 0.5 & 0.5 & 2 \\
\hline
\end{tabular}

The asterisk $\left(^{*}\right)$ corresponds to significant difference $(p<0.05)$; the double asterisk $\left.{ }^{* *}\right)$ represents significant difference $(p<0.01)$ compared to IV CANCIDAS ${ }^{\circledR}$.
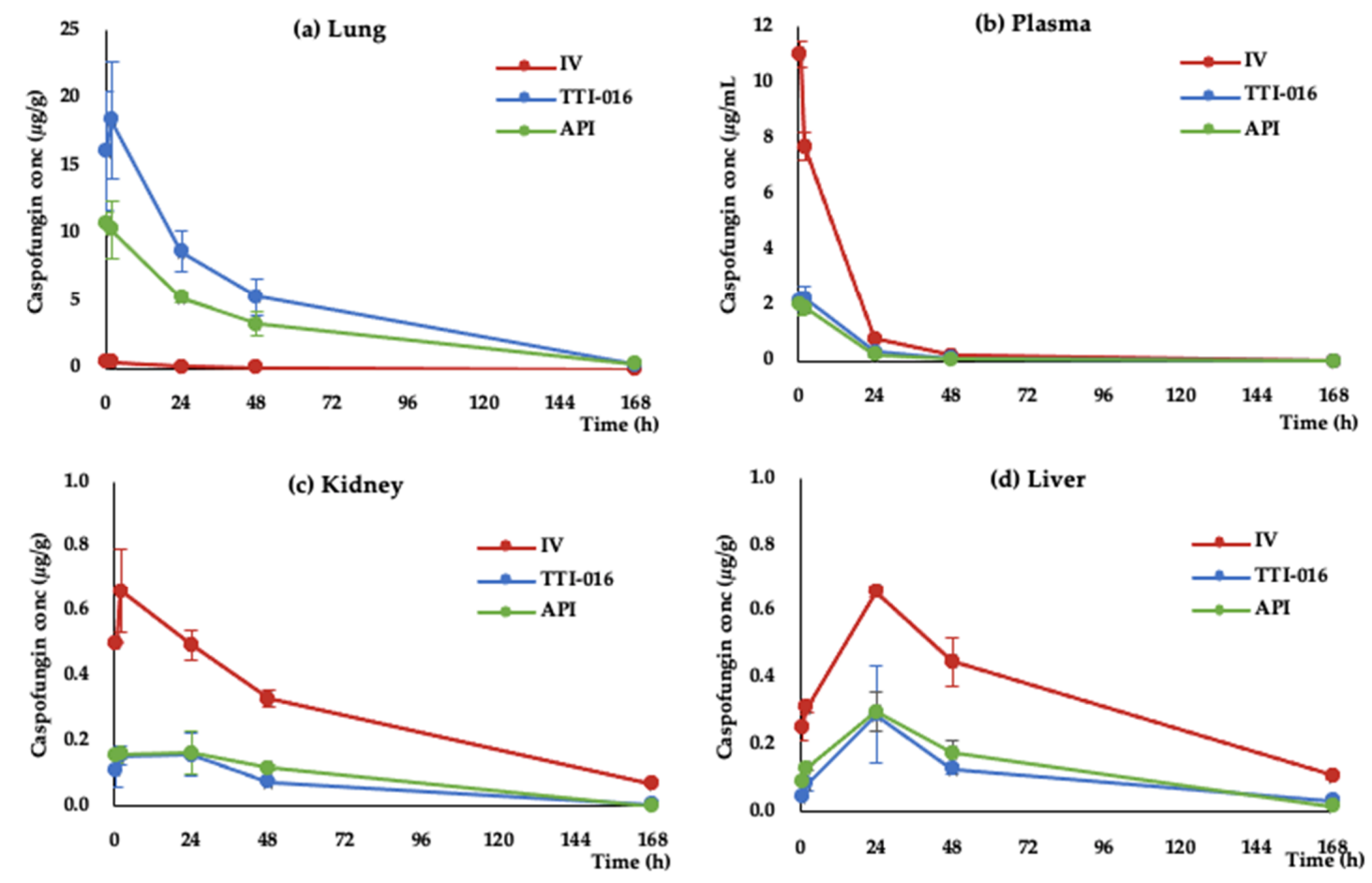

Figure 1. Time-dependent concentration curve in tissues of IV CANCIDAS ${ }^{\circledR}$, inhaled TTI-016 and API cohorts. Caspofungin concentrations were shown in (a) lung, (b) plasma, (c) kidney, and (d) liver. 
The lung $\mathrm{AUC}_{168 \mathrm{~h}}$ data also showed a $62 \%$ higher drug exposure in the inhaled TTI016 cohort compared to the inhaled API cohort $(p<0.05)$ and $4711 \%$ higher than the IV group $(p<0.01)$ (Figure 2 and Table 7 ).

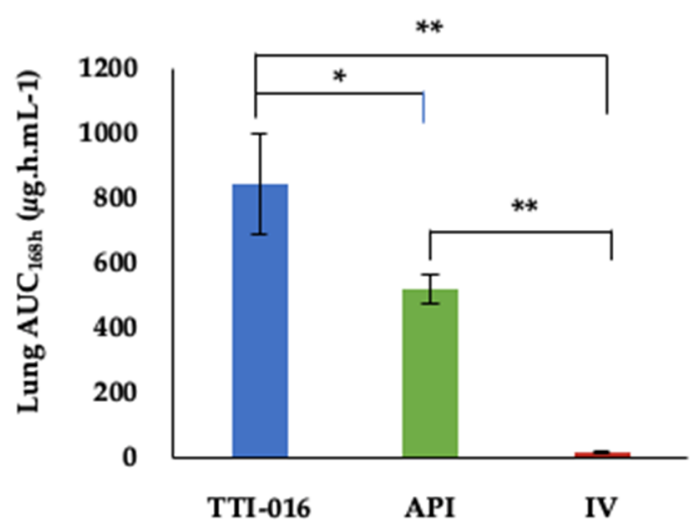

Figure 2. $\mathrm{AUC}_{168 \mathrm{~h}}$ in lung of IV CANCIDAS ${ }^{\circledR}$ and aerosolized TTI-016 and API. The data are presented as the mean values $(n=3) \pm \mathrm{SD}$. The asterisk $\left(^{*}\right)$ corresponds to significant difference $(p<0.05)$; the double asterisk $(* *)$ represents significant difference $(p<0.01)$.

\section{Discussion}

When developing a new formulation for a known drug, it is important to ensure that the drug remains as active as the existing formulation. Testing against the Candida spp., Aspergillus fumigatus and Trichophyton rubrum showed that the new formulations, TTI-016 and TTI-017, retain antifungal activity comparable to that of CANCIDAS ${ }^{\circledR}$ and the presence of formulation excipients does not interfere with antifungal activity (Table 1).

CANCIDAS $^{\circledR}$ must be stored at low temperatures (e.g., 2-8 ${ }^{\circ} \mathrm{C}$ ), and must be used within $1 \mathrm{~h}$ after reconstitution. The stability studies, presented here, show clear advantages to the new formulations, TTI-016 and TTI-017. These new lyophilized products are stable at $25{ }^{\circ} \mathrm{C}$ for at least six months or longer, and show excellent stability at $2-8{ }^{\circ} \mathrm{C}$. Furthermore, each new formulation shows better stability than simply lyophilizing caspofungin itself (Table 2). Of interest is the improved stability of TTI-016 and TTI-017 compared to TTI-014. All of these formulations have a 4:1 ratio of PVP:caspofungin. However, the lyophile diluent used is different; for TTI-016, normal saline, TTI-017, PBS and TTI-014, water. The solid-state stability of both TTI-016 and TTI-017 is superior to TTI-014, and this can be attributed to the presence of salts in the lyophilized cake matrix. These salts have a favorable effect on stability and appear to help retard the formation of caspofungin hydrolysis products arising from residual water present.

Most importantly the reconstituted solutions for TTI-016 and TTI-017 are stable at $25{ }^{\circ} \mathrm{C}$ for at least $7 \mathrm{~h}$ (Table 4 ) versus $1 \mathrm{~h}$ only for CANCIDAS ${ }^{\circledR}$, which may be problematic for an IV drug administered over $1 \mathrm{~h}$ in the hospital. At this time, it is not clear why the PVP formulation has superior reconstituted stability, but perhaps PVP is closely associated with caspofungin in solution and interferes with hydrolysis. This is under ongoing investigation.

A further criterion that may improve the efficacy of inhaled antifungal treatment is to align the aerosol particle size with the fungal spore size. Both Aspergillus and Pneumocystis spores are about 2-3 microns [1,16]. These particle sizes allow the spores to reach the alveoli in the lower airway. The new formulations are suitable for aerosolization and have the proper particle size to achieve the deep lung penetration that is associated with activity at the infection site.

CANCIDAS $^{\circledR}$ clinical efficacy with the current IV dosing may not be high enough to achieve significant distribution to the lung. Increasing the IV dose is limited by liver toxicities due to systemic distribution. The low level of drug distribution to the lung by IV delivery may be overcome by aerosolized caspofungin administered directly to the lung. In the current study, the $C_{\max }$ and AUC with the inhaled TTI-016 is 31-fold and 47-fold higher 
than with IV delivery, respectively (Table 6 and Figure 1). Moreover, TTI-016 achieves 60$70 \%$ higher $\mathrm{C}_{\max }$ and AUC in the lungs than the aerosolized API alone (Table 6). This may be due to improved aerosol characteristics and lung deposition with TTI-016. In addition to achieving superior lung AUC and $\mathrm{C}_{\max }$ with the inhaled drug, significant differences in the drug's half-life were also observed when compared to IV administration. The plasma half-life of IV caspofungin is about $11 \mathrm{~h}$, but the half-life of inhaled drug, as measured in the lung, is $18 \mathrm{~h}$ for IV CANCIDAS ${ }^{\circledR}$ versus $32 \mathrm{~h}$ with TTI-016. The difference in lung half-life between IV and inhaled TTI-016 is significant, and it is likely due to metabolizing enzymes found in plasma that are not present in the lung cavity. The aerosol delivery of TTI-016 deposits drug directly to the lung cavity. This is important as the site of action for inhibiting beta glucan synthase activity and hyphae growth and propagation is within the lung cavity. The long lung half-life may also provide an opportunity for smaller dosage and less frequent dosing schedule, which further benefit patients without sacrificing efficacy.

The targeted caspofungin MEC $_{90}$ for Aspergillus was derived from a study by the Transplant-Associated Infection Surveillance Network, where 288 Aspergillus isolates showed that more than $95 \%$ of these were susceptible to a drug concentration of $0.25 \mu \mathrm{g} / \mathrm{mL}$ [17]. Our data indicated that a single dose of inhaled TTI-016 maintained drug concentrations above this MEC for 7 days, where an IV CANCIDAS ${ }^{\circledR}$ dose could not (Figure 1a). The inhaled TTI-016 may be suitable for once-a-week administration. This weekly dosing schedule may not only provide superior coverage but also reduce patient burden in administrating caspofungin. Furthermore, the inhaled formulation and delivery could also prove useful for prophylaxis whereas daily IV delivery is not. The inhaled TTI-016 also reduced systemic drug exposure when compared to IV CANCIDAS ${ }^{\circledR}$, as shown in Figure $1 \mathrm{~b}-\mathrm{d}$. Inhaled TTI-016 minimized drug distribution to the liver and is remarkably similar in profile to the inhaled API (Figure 1d). The liver $\mathrm{C}_{\max }$ for CANCIDAS $^{\circledR}$ IV administered daily is at $24 \mathrm{~h}$ after dosing (Figure $1 \mathrm{~d}$ ). Therefore, drug continuously accumulates in the liver during the treatment period and this can lead to safety concerns, particularly when IV doses used are higher than the FDA approved dose to maximize efficacy. A balance of drug concentrations in lung and liver must be reached to accomplish the best clinical efficacy and safety profile. A once-a-week inhaled stable formulation of caspofungin may deliver an efficacious dose of drug to the lung, while minimizing liver exposure with its subsequent toxicities.

The clinical efficacy of caspofungin in treating invasive aspergillosis is highly predictable with defined PK/PD parameters, $\mathrm{C}_{\max } / \mathrm{MEC}$ and AUC/MEC ratios $[18,19]$. Invasive aspergillosis rodent models show that the animal survival and lung fungal burden reduction is achieved when $C_{\max } / \mathrm{MEC}$ ratio exceeds 10 and AUC/MEC ratio is over 330 [19]. In our study, the IV cohort did not attain the targeted PK/PD indices and predicted a weak human clinical efficacy profile (Figure 3). Several clinical trials with the standard doses of IV CANCIDAS ${ }^{\circledR}$ only showed approximately $40 \%$ human efficacy against invasive aspergillosis [7]. Based on the PK/PD indices, these patients were under dosed because of toxicity concerns at higher doses, and it is not surprising that better clinical efficacy is unattainable with IV administration. However, the inhaled TTI-016 cohort showed $\mathrm{C}_{\max } / \mathrm{MEC}$ and AUC/MEC ratios in the lung at 73 and 3376, respectively, which are indices well-above the target levels to provide clinical benefit (Figure 3). These findings support further investigation, pre-clinical inhalation toxicology studies and clinical development. 
(a) $\mathrm{AUC}_{168 \mathrm{~h}} / \mathrm{MEC}$ in Lung

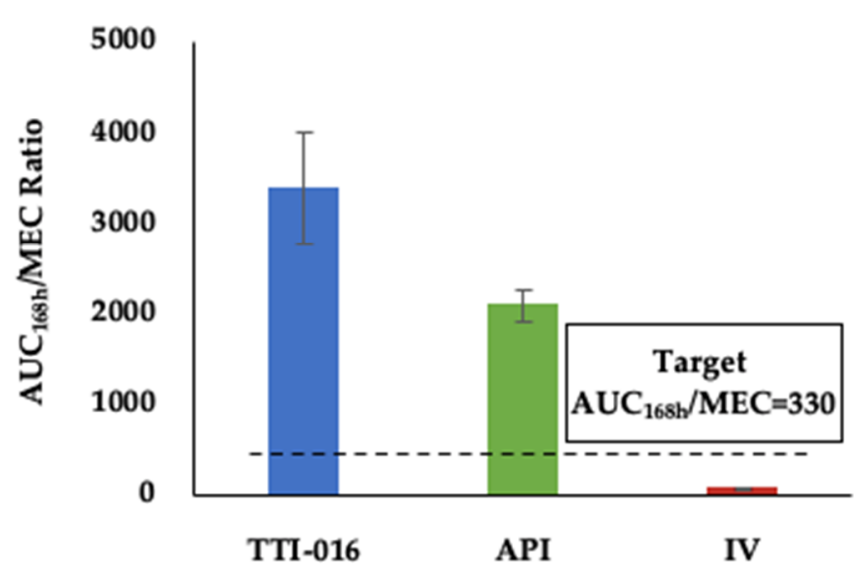

(b) $\mathrm{C}_{\max } / \mathrm{MEC}$ in Lung

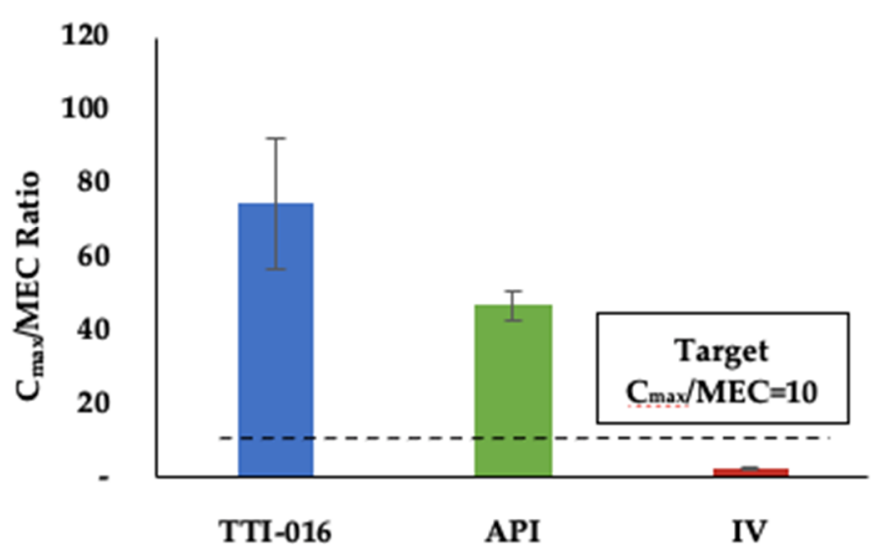

Figure 3. Comparison of PK/PD parameters in the lung between IV CANCIDAS ${ }^{\circledR}$ and aerosolized TTI-016 and API. (a) AUC/MEC ratio in lung of inhaled TTI-016, inhaled API and IV CANCIDAS ${ }^{\circledR}$. (b) $\mathrm{C}_{\max } / \mathrm{MEC}$ ratio in lung of inhaled TTI-016, inhaled API and IV CANCIDAS ${ }^{\circledR}$. The dashed line indicates the PK/PD index target level.

\section{Conclusions}

Here, we described a new inhaled formulation of caspofungin that has good solid state and reconstituted stability at room temperature. Most importantly the new formulation also increased lung drug half-life and lung exposure without increasing systemic exposure. This is critical for antifungal drug development where toxicity is often a limiting factor for human efficacy. We have addressed this issue by formulation and delivery. By direct administration to the lung, the site of fungal infection, the drug distribution characteristics met the pharmacodynamic indices associated with clinical benefit. For both PCP caused by Pneumocystis jiroveci and IPA caused by Aspergillus that exist almost exclusively in the host's lung alveoli and complete their life cycle stages in the lungs makes inhaled delivery an option for treating these diseases. The benefit to patients of the inhaled room temperaturestable formulations is the ability overcome the current challenges of antifungal drug therapy. The results illustrate how reformulation and targeted aerosol delivery may improve efficacy for the well-known antifungal drug caspofungin. Further animal toxicology studies may be pursued to support the clinical trials.

\section{Patents}

Some of this work described has been filed internationally, PCT/US2019/017520.

Supplementary Materials: The following are available online at https: / www.mdpi.com/article/ 10.3390/pharmaceutics13040504/s1, Table S1: HPLC Gradient; Table S2: Compositions of Prelyophilized Formulations; Table S3: HPLC Gradient; Table S4: Caspofungin acetate lyo solution; Table S5: pH of PVP K30 Stock Solutions in DI Water, 0.9\% Saline and PBS Buffer; Table S6: Lyophilized Caspofungin Diacetate Formulations Prepared from Water, Saline and PBS; Table S7: Target Dose and Delivery Route for the Exposure Groups; Table S8: HPLC Condition.

Author Contributions: Conceptualization, I.G.Y. and D.M.R.; methodology, I.G.Y. and D.M.R.; validation, I.G.Y. and D.M.R.; formal analysis, I.G.Y. and D.M.R.; investigation, I.G.Y. and D.M.R.; resources, I.G.Y. and D.M.R.; data curation, I.G.Y. and D.M.R.; writing—original draft preparation, D.M.R.; writing-review and editing, I.G.Y. and D.M.R.; supervision, I.G.Y. and D.M.R.; project administration, I.G.Y. and D.M.R. All authors have read and agreed to the published version of the manuscript.

Funding: This research was funded by Trilogy Therapeutics, Inc. 
Institutional Review Board Statement: The study protocols were approved by the institutional review board at Illinois Institute of Technology Research Institute (IITRI). The study also complied with all applicable sections of the Animal Welfare Act (AWA; Title 9, Code of Federal Regulations), the Public Health Service Policy on Humane Care and Use of Laboratory Animals (National Institutes of Health's Office of Laboratory Animal Welfare, 2002), and the Guide for the Care and Use of Laboratory Animals (National Research Council, 2011).

Informed Consent Statement: No human research studies were conducted.

Data Availability Statement: The data presented in this study are available in Supplementary Material.

Acknowledgments: We thank R. Narayanan and M. Muzzio, and their teams at IITRI for helpful discussions during the course of this study. We also thank J. Lim for thoughtful review of this article.

Conflicts of Interest: I.G.Y. and D.M.R. are shareholders of Trilogy Therapeutics, Inc. Trilogy Therapeutics, Inc. participates in in the design of the study; in the collection, analyses, or interpretation of data; in the writing of the manuscript, or in the decision to publish the results.

\section{References}

1. Dagenais, T.R.T.; Keller, N.P. Pathogenesis of aspergillus fumigatus in invasive aspergillosis. Clin. Microbiol. Rev. 2009, 22, 447-465. [CrossRef] [PubMed]

2. Garcia-Vidal, C.; Peghin, M.; Cervera, C.; Gudiol, C.; Ruiz-Camps, I.; Moreno, A.; Royo-Cebrecos, C.; Roselló, E.; De La Bellacasa, J.P.; Ayats, J.; et al. Causes of death in a contemporary cohort of patients with invasive aspergillosis. PLoS ONE 2015, 10, 1-10. [CrossRef] [PubMed]

3. Lin, S.-J.; Schranz, J.; Teutsch, S.M. Aspergillosis case-fatality rate: Systematic review of the literature. Clin. Infect. Dis. 2001, 32, 358-366. [CrossRef]

4. Steinbach, W.J.; Lamoth, F.; Juvvadi, P.R. Potential microbiological effects of higher dosing of echinocandins. Clin. Infect. Dis. 2015, 61, S669-S677. [CrossRef] [PubMed]

5. Yu, I.G.; O'Brien, S.E.; Ryckman, D.M. Pharmacokinetic and pharmacodynamic comparison of intravenous and inhaled caspofungin. J. Aerosol Med. Pulm. Drug Deliv. 2020, 34, 1-7. [CrossRef]

6. Desoubeaux, G.; Lemaignen, A.; Ehrmann, S. Scientific rationale for inhaled caspofungin to treat Pneumocystis pneumonia: A therapeutic innovation likely relevant to investigate in a near future. Int. J. Infect. Dis. 2020, 95, 464-467. [CrossRef] [PubMed]

7. Maertens, J.; Raad, I.; Petrikkos, G.; Boogaerts, M.; Selleslag, D.; Petersen, F.B.; Sable, C.A.; Kartsonis, N.A.; Ngai, A.; Taylor, A.; et al. Efficacy and safety of caspofungin for treatment of invasive aspergillosis in patients refractory to or intolerant of conventional antifungal therapy. Clin. Infect. Dis. 2004, 39, 1563-1571. [CrossRef] [PubMed]

8. Cornely, O.A.; Vehreschild, J.J.; Vehreschild, M.J.G.T.; Wurthwein, G.; Arenz, D.; Schwartz, S.; Heussel, C.P.; Silling, G.; Mahne, M.; Franklin, J.; et al. Phase II dose escalation study of caspofungin for invasive aspergillosis. Antimicrob. Agents Chemother. 2011, 55, 5798-5803. [CrossRef] [PubMed]

9. Zambias, R.A.; Hammond, M.L.; Heck, J.V.; Schmatz, D.M.; Nollstadt, K.M.; Trainer, C.; Abruzzo, G.; Bartizal, K. Preparation and structure-activity relationships of simplified analogs of the antifungal agent cilofungin: A total synthesis approach. J. Med. Chem. 1992, 35, 2843-2855. [CrossRef] [PubMed]

10. Govind, N.; Marlow, M. Composition for Inhalation. U.S. Patent 8,575,137 B2, 5 November 2013.

11. Usmanova, L.S.; Ziganshin, M.A.; Rakipov, I.T.; Lyadov, N.M.; Klimovitskii, A.E.; Mukhametzyanov, T.A.; Gerasimov, A.V. Microspherical particles of solid dispersion of polyvinylpyrrolidone K29-32 for inhalation administration. BioMed Res. Int. 2018, 2412156. [CrossRef] [PubMed]

12. Kariduraganavar, M.Y.; Kittur, A.A.; Kamble, R.R. Polymer Synthesis and Processing, 1st ed.; Elsevier Inc.: Amsterdam, The Netherlands, 2014; ISBN 9780123969835.

13. Jiang, J.Z.; Usayapant, A.; Bowman, D.; Kwok, K.; Peterson, J. Caspofungin Acetate Formulations. U.S. Patent 9,636,407 B2, 2 May 2017.

14. Labiris, N.R.; Dolovich, M.B. Pulmonary drug delivery. Part I: Physiological factors affecting therapeutic effectiveness of aerosolized medications. Br. J. Clin. Pharmacol. 2003, 56, 588-599. [CrossRef] [PubMed]

15. Letscher-Bru, V.; Herbrecht, R. Caspofungin: The first representative of a new antifungal class. J. Antimicrob. Chemother. 2003, 51, 513-521. [CrossRef] [PubMed]

16. Gigliotti, F.; Limper, A.H.; Wright, T. Pneumocystis. Cold Spring Harb. Prospect. Med. 2014, 4, 1-14. [CrossRef] [PubMed]

17. Lockhart, S.R.; Zimbeck, A.J.; Baddley, J.W.; Marr, K.A.; Andes, D.R.; Walsh, T.J.; Kauffman, C.A.; Kontoyiannis, D.P.; Ito, J.I.; Pappas, P.G.; et al. In vitro echinocandin susceptibility of aspergillus isolates from patients enrolled in the transplant-associated infection surveillance network. Antimicrob. Agents Chemother. 2011, 55, 3944-3946. [CrossRef] [PubMed] 
18. Ambrose, P.G.; Bhavnani, S.M.; Rubino, C.M.; Louie, A.; Gumbo, T.; Forrest, A.; Drusano, G.L. PharmacokineticsPharmacodynamics of Antimicrobial Therapy: It's not just for mice anymore. Clin. Infect. Dis. 2007, 44, 79-86. [CrossRef] [PubMed]

19. Wiederhold, N.P.; Kontoyiannis, D.P.; Chi, J.; Prince, R.A.; Tam, V.H.; Lewis, R.E. Pharmacodynamics of Caspofungin in a murine model of invasive pulmonary aspergillosis: Evidence of concentration-dependent activity. J. Infect. Dis. 2004, 190, 1464-1471. [CrossRef] [PubMed] 